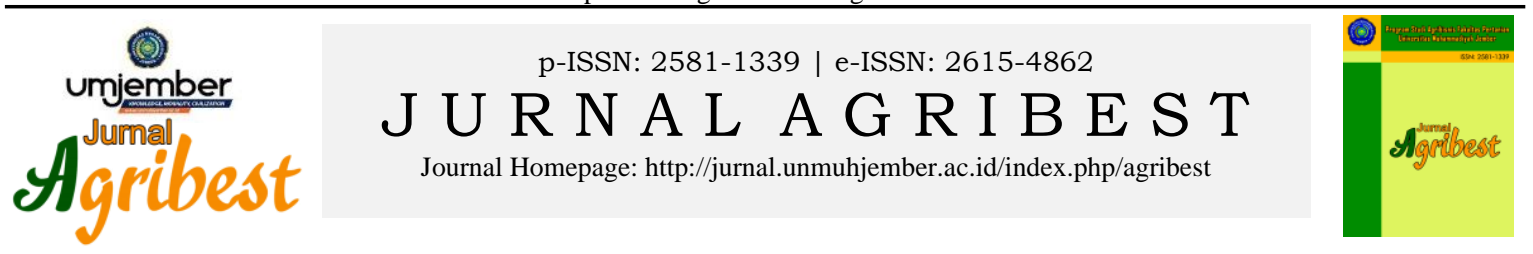

\title{
Analisis Pemasaran Lebah Madu Klanceng (Trigona sp.) di Kecamatan Pagerwojo Kabupaten Tulungagung pada Masa Pandemi Covid-19
}

\author{
Marketing Analysis of Klanceng Honey Bees (Trigona sp.) In Pagerwojo \\ District, Tulungagung Regency during the Covid-19 Pandemic \\ Nastiti Winahyu, Fajar Amirudin , Imazunita Nur Azizah \\ Universitas Islam Kadiri \\ email: nastitiwinahyu@gmail.com, imazunita731@gmail.com
}

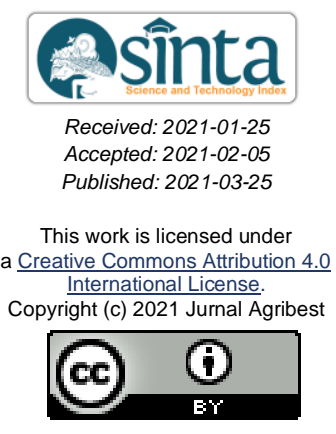

Corresponding Author: Nastiti Winahyu, Universitas Islam Kadiri, nastitiwinahyu@gmail.com

\section{ABSTRAK}

Penelitian ini dilakukan untuk mengetahui saluran pemasaran dan efisiensi pemasaran komoditas lebah madu klanceng (Trigona sp.) di Kecamatan Pagerwojo Kabupaten Tulungagung. Penentuan responden dipilih menggunakan metode purposive sampling (32 peternak anggota kelompok tani hutan), snowball sampling ( 2 pedagang pengecer) dan accidental sampling (3 konsumen). Analisis data mencakup analisis margin, producer's share, dan rasio efisiensi keuntungan terhadap biaya pemasaran. Berdasarkan hasil penelitian, terdapat 2 pola saluran pemasaran. Pola saluran I produk madu : peternak - konsumen. Pola saluran II produk madu: produsen - pedagang pengecer - konsumen. Hasil analisis menunjukkan pemasaran langsung lebih efisien. Saluran Pola I memperoleh producer's share dan rasio efisiensi keuntungan terhadap biaya yang lebih tinggi sebesar 100 persen dan 26,63 dibanding Pola II sebesar 90 persen dan 18.01.

Kata Kunci : efisiensi, klanceng, marjin, producer's share, saluran pemasaran

\section{ABSTRACT}

This research was conducted to determine the marketing pattern and marketing efficiency of the honey bee klanceng (Trigona sp.) commodity in Pagerwojo District, Tulungagung Regency. Respondents selected using method of purposive sampling (32 farmers who are members of the forest farmers group), snowball sampling (2 retailers) and accidental sampling (3 consumers). Data analysis includes analysis of margins, producer's share, and the ratio efficiency of profit to marketing costs. Based on the research results, there are 2 marketing patterns (MP). MP I of honey products: producers - consumers. MP II of honey products: producers - retailers - consumers. The analysis shows that direct marketing is more efficient. MP I obtained producer's share and profitability ratio by 100 percent and 26.63. That is higher than MP II producer's share and profitability ratio by 90 percent and 18.01 .

Keywords: efficiency, klanceng, margin, marketing patterns, producer's share 


\section{PENDAHULUAN}

Indonesia dikenal memiliki potensi yang cukup besar dalam pengembangan komoditas lebah. Komoditas tersebut merupakan kekayaan sumber daya alam hayati dengan berbagai potensi ragam jenis tumbuhan yang dapat digunakan sebagai sumber pakan dengan didukung kondisi agroklimat sebagai penunjang aktivitas lebah. Iklim tropis memungkinkan tersedianya bunga sepanjang tahun sehingga sumber pakan terjamin dan lebah dapat menghasilkan madu dengan baik.

Madu memiliki rasa, nilai gizi dan khasiatnya yang tinggi sehingga baik untuk dikonsumsi. Khasiat madu digemari oleh banyak orang sebagai jenis makanan yang unik sekaligus bersifat obat serta sanggup memberikan tambahan tenaga bagi tubuh. Secara tradisional, madu telah lama digunakan untuk tujuan medis dan therapis, serta perawatan kecantikan dan keperluan industri. Lebah madu tidak hanya menghasilkan madu saja tetapi juga dapat menghasilkan produk lain seperti lilin lebah, royal jelly dan bee pollen yang memiliki manfaat dan nilai jual tinggi.

Madu memiliki prospek usaha yang baik dengan pangsa pasar yang luas sehingga banyak peternak yang berkompetisi dalam persaingan di bidang usaha ternak lebah madu. Produk hasil lebah sangat menjanjikan jika digunakan sebagai peluang usaha,sehingga masih banyak peternak lebah madu yang menjual madunya tanpa memikirkan kualitasnya yang membuat posisi petani lebah menjadi lemah. Standar mutu madu yang berlaku di Indonesia ditetapkan oleh Badan Standarisasi Nasional (BSN) untuk menjamin mutu dan keamanan produk di pasaran (Adalina, 2017). Proses produksi harus terus diperbaiki agar proses perizinan dapat dilakukan sesuai dengan standarisasi SNI (Wahyudi \& Nuddin, 2019).

Pemasaran madu yang sering dilakukan peternak adalah menjual produknya secara langsung kepada konsumen. Sebagian peternak madu menjual produk dalam bentuk curah/botol tanpa merek dan ukuran tertentu. Hal ini disebabkan pengetahuan produsen madu terkait serapan teknologi pengolahan dan pemasaran produk masih kurang. Menurut Setiawan, Sulaeman, \& Arlita (2016), strategi pengembangan usaha produk madu yaitu membuat madu yang berkualitas, menciptakan produk madu unggulan dan mempertahankan keaslian dan kemurnian madu serta meningkatkan produktivitas madu agar meningkatnya loyalitas konsumen.

Pada aspek pemasaran, kondisi yang paling sulit adalah mempertahankan konsumen untuk selalu menggunakan produk unggulan antara lain dengan menciptakan loyalitas bagi pelanggan dan menjaga ketersediaan serta konsistensi kualitas produk madu. Menurut Srikalimah, Akbar, \& Jauhari (2018), peningkatan kualitas madu dan diversifikasi produk dapat membuat harga jual madu lebih tinggi. Penerapan diversifikasi produk turunan madu meningkatkan nilai tambah dan memberikan peningkatan pendapatan (Amar, Dwiningsih, \& Humaerah, 2017). Hal tersebut berimplikasi pada pemasaran madu untuk mencapai pasar yang lebih luas dari segi jarak maupun harga jual.

Kecamatan Pagerwojo Tulungagung memiliki wilayah yang potensial untuk pengembangan budidaya lebah madu klanceng (Trigona sp.). Wilayah ini berada di dataran tinggi dan memiliki area hutan yang luas yaitu 5.388 hektar. Hal ini baik untuk pembudidayaan lebah madu klanceng. dalam ketersediaan pakan dan pemeliharaan. Usaha budidaya lebah madu klanceng menguntungkan dan layak untuk dilanjutkan (Pratiwi, Abdullah, \& Dirgantoro, 2020). Pembudidayaan lebah madu ini dapat menjadi bagian dari mata pencaharian masyarakat yang tinggal di pedesaan dan sekitar hutan untuk meningkatkan pendapatan keluarga.

Budidaya lebah madu masih dilakukan secara tradisional dengan menggunakan stup berbahan kayu atau bambu dengan ukuran yang berbeda-beda. Begitupula pada pemasaran langsung ke konsumen. Guna mengatasi persaingan pasar yang kompetitif diperlukan keunggulan dalam hal kualitas maupun kuantitas produk (Juniani, 2017). Budidaya lebah madu yang dijalankan telah membentuk kelompok tani peternak madu. Pemasaran melalui kelompok dapat memberikan keuntungan bagi anggotanya dan nilai tambah produk (Sedana \& Astawa, 2016). Hal ini memerlukan identifikasi terkait bauran pemasaran yang mencakup 4P (product, price, place, promotion) sehingga peternak dapat mengetahui potensi yang bisa dihasilkan.

Indikator keberhasilan pemasaran suatu produk lebah madu adalah sistem pemasaran yang berlangsung secara efisien. Sistem pemasaran bisa menjual produk madu secara luas dengan biaya yang seminimal mungkin sehingga selisih harga dari produsen ke konsumen tidak terlalu tinggi. Namun, pola konsumsi dan daya beli masyarakat mengalami perubahan sejak Indonesia khususnya 
Jawa Timur yang terdampak oleh pandemi Covid-19. Hal ini diperkirakan akan mempengaruhi tingkat harga maupun saluran pemasaran dari komoditas madu yang diusahakan.

Tinggi rendahnya tingkat harga yang diterima produsen yang erat kaitannya dengan saluran pemasaran yang terbentuk. Selain itu efisiensi pemasaran didasarkan pula pada nilai marjin, producer's share, dan rasio keuntungan terhadap biaya. Oleh sebab itu, pada masa pandemi Covid-19 penting untuk diteliti terkait bauran dan saluran pemasaran serta efisiensi pemasaran dari komoditas lebah madu klanceng (Trigona sp.) di Kecamatan Pagerwojo Kabupaten Tulungagung.

\section{Lokasi dan Waktu Penelitian}

\section{METODE PENELITIAN}

Penelitian dilaksanakan pada bulan Agustus - November 2020 di Kecamatan Pagerwojo Kabupaten Tulungagung. Pemilihan lokasi dilakukan secara sengaja (purposive) dengan pertimbangan bahwa Kecamatan Pagerwojo Kabupaten Tulungagung berpotensi untuk pengembangan peternakan lebah madu klanceng didukung dengan potensi sumber makanan yang tersedia.

\section{Pengambilan dan Sumber Data}

Metode penelitian yang digunakan adalah metode survei. Metode survei merupakan metode penelitian yang mengambil sampel dari beberapa populasi. Sampel yang digunakan pada penelitian yaitu produsen atau peternak lebah madu sebanyak 32 orang yang terdiri dari 2 Kelompok Tani Hutan (KTH Wana Bakti dan KTH Sumber Lestari) yang beranggotakan masingmasing 16 orang. Sampel ini dipilih menggunakan metode purposive sampling.

Data pemasaran juga diambil dari lembaga pemasaran yang digunakan peternak lebah madu klanceng untuk memasarkan hasil panennya. Metode penentuan responden untuk Lembaga Pemasaran dengan menggunakan metode snowball sampling yaitu penelusuran saluran pemasaran produk madu yang ada di Kecamatan Pagerwojo Kabupaten Tulungagung mulai dari produsen sampai konsumen akhir berdasarkan informasi yang diberikan produsen dan pelaku pemasaran. Responden yang digunakan dalam penelitian saluran pemasaran yaitu 2 orang pedagang dan 3 orang konsumen (accidental sampling).

Penelitian ini menggunakan data primer dan sekunder. Data primer diperoleh melalui wawancara menggunakan kuisioner meliputi data karakteristik responden, saluran pemasaran, harga beli, harga jual, fungsi pemasaran, informasi pasar, dan kendala pemasaran. Sedangkan data sekunder diperoleh dari jurnal, prosiding, buku, dan referensi yang relevan dengan penelitian ini. Data sekunder digunakan sebagai pendukung data primer dan keseluruhan penelitian.

\section{Analisis Data}

Marjin pemasaran yaitu selisih antara harga jual dan harga beli. Ada dua komponen dalam marjin pemasaran yaitu komponen biaya dan komponen keuntungan sehingga rumusnya sebagai berikut:

$$
\begin{aligned}
& \mathrm{Mm}=\pi+\mathrm{C} \ldots \\
& \mathrm{Ps}-\mathrm{Pb}=\pi+\mathrm{C} \\
& \pi=\mathrm{Ps}-\mathrm{Pb}-\mathrm{C}
\end{aligned}
$$

dimana:

$\mathrm{Mm} \quad=$ Marjin pemasaran (Rp/satuan)

Ps = Harga jual (Rp/satuan)

$\mathrm{Pb} \quad=$ Harga beli $(\mathrm{Rp} / \mathrm{satuan})$

$\pi \quad=$ Keuntungan (Rp/satuan)

$\mathrm{C} \quad=$ Biaya pemasaran (Rp/satuan)

Producer's share adalah bagian yang diterima produsen dari harga yang dibayarkan konsumen akhir. Secara matematis dirumuskan sebagai berikut: 
dimana:

$$
\begin{aligned}
\mathrm{PS} & =\text { Producer's share (persen) } \\
\mathrm{Pp} & =\begin{array}{l}
\text { Harga yang diterima produsen } \\
\text { (Rupiah) }
\end{array} \\
\mathrm{Pc} & =\begin{array}{l}
\text { Harga yang dibayarkan oleh } \\
\text { konsumen akhir (Rupiah) }
\end{array}
\end{aligned}
$$

Rasio keuntungan terhadap biaya pemasaran merupakan besaran yang diterima lembaga pemasaran sebagai imbalan atas biaya pemasaran yang dikeluarkan. Secara matematis dirumuskan sebagai berikut:

$$
\text { Rasio Keuntungan terhadap Biaya }=\pi / \text { C..(5) }
$$

dimana :

$$
\begin{array}{ll}
\pi & : \text { Keuntungan (Rp/satuan) } \\
\mathrm{C} & \text { : Biaya pemasaran (Rp/satuan) }
\end{array}
$$

\section{Gambaran Umum Responden}

\section{HASIL DAN PEMBAHASAN}

Responden penelitian tergabung dalam Kelompok Tani Hutan (KTH) yaitu KTH Wana Bakti dan KTH Sumber Lestari. Kelompok tersebut beranggotakan masing-masing 16 anggota. Mayoritas responden berjenis kelamin laki-laki (90,63 persen). Rata-rata umur responden peternak madu klanceng berkisar antara 23 - 74 tahun dengan mayoritas (45 persen) berada pada rentang umur 36-50 tahun. Rata-rata pengalaman dalam beternak lebah klanceng yaitu 3,5 tahun.

Usaha lebah madu klanceng termasuk usaha sampingan karena sebagian besar responden memiliki pekerjaan utama diluar peternakan seperti pertanian, PNS, swasta, dll. Usaha ini dapat digunakan sebagai tambahan pemasukan bagi peternak karena tidak memerlukan proses pemeliharaan yang sulit. Kajian lain dilakukan oleh Yunita, Pordamantra, \& Pisi (2019) yang mengungkap bahwa anggota kelompok memiliki pekerjaan utama sebagai petani dan kegiatan budidaya lebah madu hanya dijadikan sebagai pekerjaan sampingan mereka. Menurut Hapsari, Djuwendah, \& Supriyadi (2018) serta Dewantari \& Suranjaya (2019), pemberdayaan kelompok secara partisipatif dapat meningkatkan pendapatan petani melalui peningkatan pengetahuan dan keterampilan budidaya serta manajemen usaha. Pengelolaan kelestarian hutan akan menjaga ketersediaan pakan lebah madu. Kesadaran masyarakat dalam melestarikan kearifan lokal dengan tidak melakukan penebangan pohon, pembakaran hutan, dan pembukaan lahan secara liar sebagai upaya pelestarian habitat dan ketersediaan pakan lebah madu hutan (Sofia, Zainal, \& Roslinda, 2017).

\section{Karakteristik Lembaga Pemasaran}

Lembaga pemasaran yang terlibat pada peternakan lebah madu klanceng adalah kelompok ternak, pedagang pengecer, dan konsumen (individu). Kelompok ternak berperan dalam mengkoordinir/ mengumpulkan hasil madu dari anggota peternak. Pedagang pengecer merupakan perantara dalam saluran pemasaran. Pedagang pengecer mendapatkan produk dari produsen. Konsumen adalah setiap orang yang memakai produk madu klanceng yang tersedia untuk kepentingan diri sendiri, keluarga tetapi tidak untuk diperjualbelikan.

\section{Bauran Pemasaran}

Bauran pemasaran komoditas madu klanceng di Kecamatan Pagerwojo sebagai berikut :

1. Produk

Produk yang dihasilkan usaha peternakan lebah madu klanceng adalah madu yang dikemas pada botol berukuran $150 \mathrm{ml}$. Informasi produk dilengkapi dengan label/stiker. Pengemasan produk yang menarik dapat menarik komsumen untuk membeli produk (Sahureka, Siahaya, \& 
Imlabla, 2019). Responden mengetahui bahwa kemasan yang baik dengan disertai label/stiker akan meningkatkan nilai tambah produk. Berdasarkan hasil penelitian, produksi madu yang dihasilkan dalam kurun waktu 1 tahun sebanyak 604 botol.

Selain madu, terdapat 3 peternak yang menjual produk berupa stup kayu dan koloni. Belum terdapat produk turunan dari lebah madu klanceng di Kecamatan Pagerwojo. Lebah madu klanceng juga memiliki potensi produk turunan. Bee polen dapat menjadi produk turunan dari usaha budidaya lebah madu klanceng (Wibawanti, Mudawaroch, \& Pamungkas, 2020). Produk lebah madu klanceng dapat dilihat pada Gamb

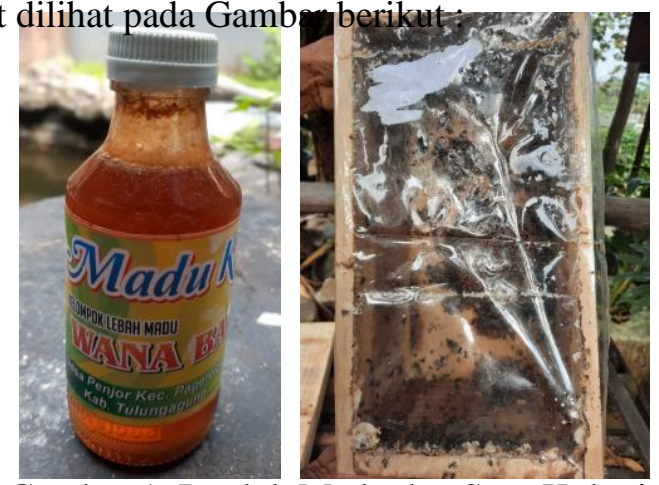

Gambar 1. Produk Madu dan Stup Koloni

\section{Harga}

Harga dari produk madu klanceng seharga Rp 85.000 per botol di peternak. Harga produk meningkat disaat terjadi wabah Covid-19 menjadi Rp 90.000 per botol di peternak. Perbedaan harga disebabkan permintaan yang tinggi. Permintaan pada masa pandemi Covid-19 sangat banyak setiap bulan namun produksi madu belum mampu mencukupi permintaan. Produk dicari konsumen untuk meningkatkan imunitas tubuh. Produksi madu paling banyak berada pada musim penghujan mulai bulan Oktober - Maret. Musim bunga mekar sehingga ketersediaan pakan terjamin. Harga produk usaha peternakan lebah madu klanceng pada masa sebelum dan saat pandemi Covid-19 dapat dilihat pada tabel berikut :

Tabel 1.Harga produk peternakan lebah madu klanceng di Kecamatan Pagerwojo Kab. Tulungagung

\begin{tabular}{|l|r|r|}
\hline \multicolumn{1}{|c|}{ Produk } & $\begin{array}{c}\text { Harga Sebelum Pandemi } \\
(\mathrm{Rp})\end{array}$ & \multicolumn{2}{c|}{ Saat Pandemi (Rp) } \\
\hline Tingkat Peternak & 85.000 & 90.000 \\
\hline Madu & 130.000 & 140.000 \\
\hline Stup dan Koloni & 90.000 & 100.000 \\
\hline Tingkat Pengecer & 135.000 & 150.000 \\
\hline Madu & \multicolumn{2}{|c|}{} \\
\hline Stup dan Koloni &
\end{tabular}

Harga produk stup dan koloni sebesar Rp 140.000,00 pada masa pandemi Covid-19 di peternak. Harga meningkat dibandingkan sebelum pendemi dengan kisaran harga Rp $100.000,00$ - Rp 130.000,00. Sebelum melakukan penjualan produk, peternak telah mengetahui informasi harga dari peternak lain maupun kelompok tani.

\section{Tempat}

Sebagian besar anggota kelompok menjual produk dengan cara menitipkan kepada kelompok ternak. Ketua kelompok berperan untuk membantu penjualan produk dari anggota kelompok. Terdapat anggota yang menjual produk madu langsung ke konsumen secara langsung di lokasi peternakan tersebut. Namun, ada pula konsumen yang memesan (pre-order) terlebih dahulu. Beberapa konsumen menunda pembelian karena produk belum tersedia. Apabila produk telah tersedia, kelompok tani akan menginfokan hal tersebut. Transaksi produk dilakukan secara tunai saat barang dipertukarkan. 


\section{Promosi}

Strategi promosi yang masih bersifat konvensional yaitu konsumen menghubungi peternak langsung. Penjualan belum menggunakan media sosial seperti Facebook, Instagram, Shopee atau lainnya. Promosi masih terbatas dengan menggunakan Telepon, SMS, dan Whatsapp. Promosi juga dibantu oleh dinas terkait agar produk dapat dikenal oleh masyarakat. Promosi yang dilakukan yaitu mengikut sertakan produk pada pameran atau bazar produk pertanian. Penelitian Suherman, Kadarsih, \& Gusmantoro (2017) menunjukkan bahwa strategi pemasaran meliputi peningkatan penjualan produk didukung dengan kegiatan promosi, distribusi, layanan konsumen dan variasi produk.

\section{Fungsi Pemasaran}

Fungsi pemasaran meliputi fungsi pertukaran, fisik, dan fasilitas. Fungsi pemasaran yang dilakukan oleh peternak dan pengecer adalah pembelian, penjualan, dan penetapan harga. Fungsi fisik yang dilakukan yatu transportasi, penyimpanan, dan penanganan. Serta penanggungan risiko dan pembiayaan sebagai fungsi fasilitas.

\section{Saluran Pemasaran}

Saluran pemasaran usaha peternakan lebah madu klanceng (Trigona sp.) di Kecamatan Pagerwojo Kabupaten Tulungagung terbagi menjadi 2 saluran yaitu :

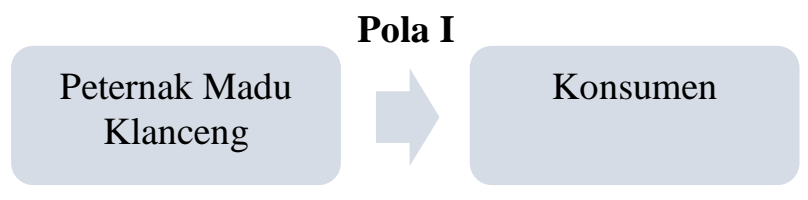

\section{Gambar 2. Pola Saluran Pemasaran I}

Saluran pemasaran pola I di peternakan lebah madu klanceng Kecamatan Pagerwojo Kabupaten Tulungagung hanya melibatkan produsen dan konsumen. Konsumen membeli produk madu langsung ke lokasi peternak. Konsumen terlebih dahulu menghubungi peternak untuk memesan produk. Konsumen dalam saluran pemasaran pola I adalah tetangga dan pelanggan yang berlokasi tidak jauh dari peternak. Peternak menjual madu ke konsumen dalam bentuk botol dengan ukuran $150 \mathrm{ml}$. Pada masa pandemi Covid-19 harga yang diperoleh konsumen dari peternak seharga $\mathrm{Rp} 90.000,00$ per botol. Sedangkan pada produk stup dan koloni, Konsumen membeli langsung ke lokasi peternak dengan harga Rp 140.000,00. Konsumen terlebih dahulu menghubungi peternak untuk memesan produk.

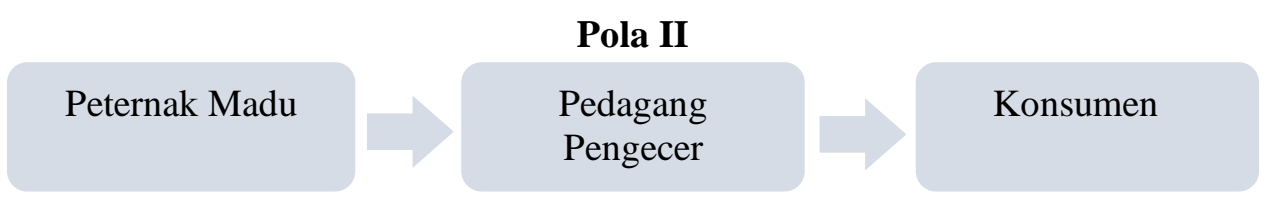

Gambar 3. Pola Saluran Pemasaran II

Pada saluran pemasaran pola II ini, pemasaran produk madu klanceng dimulai dari pedagang pengecer yang mendatangi peternak untuk membeli produk madu. Pedagang pengecer kemudian menjual langsung ke konsumen akhir dalam bentuk botol $150 \mathrm{ml}$. Harga madu yang dibeli pedagang pengecer dari peternak sebesar Rp.90.000,00/botol. Pedagang pengecer menjual ke konsumen akhir dengan harga madu Rp.100.000,00 per botol pada masa pandemi Covid-19. Saluran pemasaran ini dilakukan dengan cara pembelian langsung yang dilakukan di lokasi peternak atau pengecer. Sedangkan pada produk stup dan koloni, konsumen membeli seharga Rp $150.000,00$. 


\section{Analisis Marjin dan Producer's Share}

Menurut Soekartawi (2002), syarat saluran tataniaga dikatakan efisien yaitu saluran menyampaikan hasil-hasil dari produsen dengan biaya semurah-murahnya dan mengadakan pembagian yang adil dalam keseluruhan harga yang dibayarkan konsumen akhir kepada semua pihak yang ikut dalam kegiatan produksi maupun pemasaran. Biaya yang dikeluarkan oleh peternak dalam menjual produk madu klanceng meliputi botol dan label. Biaya transportasi dan operasional kendaraan tidak dibebankan pada Saluran Pola I karena biaya tersebut dikeluarkan dalam proses penjualan barang melalui pengecer yaitu pada saluran II. Rincian biaya, marjin, producer's share produk madu klanceng dapat dilihat pada tabel berikut :

Tabel 2. Biaya, Marjin, dan Producer's Share peternakan lebah madu klanceng di Kec. Pagerwojo Kab. Tulungagung

\begin{tabular}{|c|c|c|c|c|c|}
\hline No. & Keterangan & $\begin{array}{l}\text { Saluran Pola I } \\
\text { Rp/botol }\end{array}$ & $\%$ & $\begin{array}{c}\text { Saluran Pola II } \\
\text { Rp/botol }\end{array}$ & $\%$ \\
\hline \multicolumn{6}{|c|}{ Produsen } \\
\hline 1 & Biaya Produksi & 30.600 & 34,00 & 30.600 & 30,60 \\
\hline \multirow[t]{4}{*}{2} & Biaya Pemasaran & & & & \\
\hline & a. Botol & 2.000 & & 2.000 & \\
\hline & b. Label/ Stiker & 150 & & 150 & \\
\hline & Total Biaya & 2.150 & 2,39 & 2.150 & 2,15 \\
\hline 3 & Keuntungan & 57.250 & 63,61 & 57.250 & 57,25 \\
\hline 4 & Harga Jual & 90.000 & 100,00 & 90.000 & 90,00 \\
\hline \multicolumn{6}{|c|}{ Pedagang Pengecer } \\
\hline 1 & Harga Beli & & & 90.000 & 90,00 \\
\hline \multirow[t]{4}{*}{2} & Biaya Pemasaran & & & & \\
\hline & a. Transportasi & & & 1.000 & \\
\hline & b. Promosi & & & 500 & \\
\hline & Total Biaya & & & 1.500 & 1,50 \\
\hline 3 & Keuntungan & & & 8.500 & 8,50 \\
\hline 4 & Marjin Pemasaran & & & 10.000 & 10,00 \\
\hline 5 & Harga Jual & & & 100.000 & 100,00 \\
\hline \multicolumn{6}{|c|}{ Konsumen Akhir } \\
\hline 1 & Harga Beli & 90.000 & 100,00 & 100.000 & 100,00 \\
\hline Tota & Marjin & 0 & 0,00 & 10.000 & 10,00 \\
\hline Tota & Biaya & 2.150 & 2,39 & 3.650 & 3,65 \\
\hline Tota & Keuntungan & 57.250 & 63,61 & 65.750 & 65,75 \\
\hline Keur & Ingan/Biaya & 26,63 & & 18,01 & \\
\hline Prod & er's Share & & 100,00 & & 90,00 \\
\hline
\end{tabular}

Sumber : Data Primer diolah (2020)

Berdasarkan hasil penelitian diperoleh bahwa saluran pemasaran yang paling efisien berdasarkan biaya pemasaran, marjin, dan producer's share untuk madu klanceng di Kecamatan Pagerwojo adalah saluran Pola I. Hal ini selaras dengan penelitian Trismawan, Utami, \& Nugroho (2015) bahwa pemasaran langsung menunjukkan nilai yang lebih efisien. Saluran Pola I memperoleh producer's share dan rasio efisiensi keuntungan terhadap biaya yang lebih tinggi sebesar 100 persen dan Rp 26,63/botol dibanding Pola II sebesar 90 persen dan Rp 18,01/botol.

\section{Kendala}

Terdapat beberapa kendala yang dihadapi oleh peternak madu klanceng, antara lain :

1. Produk bersifat musiman sehingga ketersediaan produk tidak selalu ada.

2. Produksi yang dihasilkan masih terbatas sehingga permintaan yang tinggi belum mampu terpenuhi.

3. Promosi masih terbatas dan belum merambah pasar online. 
Jurnal Agribest Volume X Nomor X (2020) Hal: 25-32

DOI: https://doi.org/ 10.32528/agribest.v5i1.4198

KESIMPULAN

Berdasarkan hasil penelitian dapat disimpulkan bahwa terdapat 2 pola saluran pemasaran. Pola saluran I produk madu : peternak - konsumen. Pola saluran II produk madu : produsen pedagang pengecer - konsumen. Nilai marjin pola saluran I sebesar nol dengan producer's share 100 persen. Pola saluran II diperoleh marjin sebesar Rp 10.000,00 dan producer's share sebesar 90 persen. Nilai rasio efisiensi keuntungan terhadap biaya pada pola saluran I dan II secara berturut sebesar 26,63 dan 18,01. Hasil analisis menunjukkan pemasaran langsung (Pola I) lebih efisien berdasarkan nilai marjin, producer's share, dan rasio efisiensi keuntungan terhadap biaya.

\section{DAFTAR PUSTAKA}

Adalina, Y. (2017). Kualitas madu putih asal Provinsi Nusa Tenggara Barat. Prosiding Seminar Nasional Masyarakat Biodiversitas Indonesia, 3, pp. 189-193. doi:10.13057/psnmbi/m030204

Amar, F. N., Dwiningsih, E., \& Humaerah, A. D. (2017). Analisis Nilai Tambah Produk Turunan Madu Pada CV. Madu Apiari Mutiara Cimanggis, Depok, Jawa Barat. Jurnal Agribisnis, 11(5), 62-76. doi:10.15408/aj.v11i1.11834

Dewantari, M., \& Suranjaya, I. (2019). Pengembangan Budidaya Lebah Madu Trigona spp Ramah Lingkungan di Desa Antapan Kecamatan Baturiti Kabupaten Tabanan. Buletin Udayana Mengabdi, 18(1). Retrieved from https://ojs.unud.ac.id/index.php/jum/article/view/46368

Hapsari, H., Djuwendah, E., \& Supriyadi, Y. (2018). Optimalisasi Manajemen Usaha Lebah Madu untuk Meningkatkan Pendapatan Keluarga (Kasus pada Kelompok Tani Sunda Mukti, Desa CIlengkrang, Kecamatan Cilengkrang, Kabupaten Bandung). Dharmakarya : Jurnal Aplikasi Ipteks untuk Masyarakat, 7(1), 46-50. Retrieved from http://jurnal.unpad.ac.id/dharmakarya/article/view/11878/7708

Juniani, N. K. (2017). Bauran Pemasaran Madu Capalau Karangasem Pada Kelompok Tani Hutan Capalau di Desa Abang Kabupaten Karangasem. dwijenAGRO, 7(2), 61-67. Retrieved from http://garuda.ristekbrin.go.id/documents/detail/1757494

Pratiwi, N. P., Abdullah, B., \& Dirgantoro, M. A. (2020). Analisis Produktivitas, Keuntungan, dan Efisiensi Biaya Usaha Budidaya Lebah Madu Trigona sp. di Kecamatan Landono Kabupaten Konawe Selatan. Jurnal Ilmiah Membangun Desa dan Pertanian (JIMDP), 5(3), 111-116. doi:10.37149/jimdp.v5i3.11026

Sahureka, M., Siahaya, T., \& Imlabla, W. N. (2019). Pengembangan Produksi dan Pemasaran Madu Wetar. Jurnal Hutan Pulau-Pulau Kecil, 3(2), 177-185. doi:10.30598/jhppk.2019.3.2.177

Sedana, G., \& Astawa, N. D. (2016). Panca Datu Partnership in Support of Inclusive Business for Coffee Development: The Case of Ngada District, Province of Nusa Tenggara Timur, Indonesia. Asian Journal of Agriculture and Development, 13(2), 75-88. doi:10.22004/ag.econ.258966

Setiawan, A., Sulaeman, R., \& Arlita, T. (2016). Strategi Pengembangan Usaha Lebah Madu Kelompok Tani Setia Jaya di Desa Rambah Jaya Kecamatan Bangun Purba Kabupaten Rokan Hulu. Jurnal Online Mahasiswa Faperta, 3(3). Retrieved from https://jom.unri.ac.id/index.php/JOMFAPERTA/article/view/9514

Soekartawi. (2002). Prinsip Dasar Manajemen Pemasaran Hasil-hasil Pertanian, Teori dan Aplikasinya (1 ed.). Jakarta: Raja Grafindo Persada. 
Jurnal Agribest Volume X Nomor X (2020) Hal: 25-32

DOI: https://doi.org/ 10.32528/agribest.v5i1.4198

Sofia, Zainal, S., \& Roslinda, E. (2017). Pengelolaan Madu Hutan Berbasis Kearifan Lokal Masyarakat di Desa Semalah dan Desa Melemba Kawasan Danau Sentarum Kabupaten Kapuas Hulu. Jurnal Hutan Lestari, 5(2), 209-216. doi:10.26418/jhl.v5i2.19096

Srikalimah, Akbar, M., \& Jauhari, A. (2018). Peningkatan Kualitas dan Diversifikasi Produk Madu di Desa Sukarame Kecamatan Mojoroto Kota Kediri Jawa Timur. Amaliah: Jurnal Pengabdian Kepada Masyarakat, 2(2), 208-216. doi:10.32696/ajpkm.v2i2.204

Suherman, D., Kadarsih, S., \& Gusmantoro, M. (2017). Strategi Pemasaran Madu Berdasarkan Karakteristik Konsumen di Kota Bengkulu. Jurnal Sain Peternakan Indonesia (JSPI), 12(2), 171-183. doi:10.31186/jspi.id.12.2.171-183

Trismawan, U. I., Utami, H. D., \& Nugroho, B. A. (2015). Analisis Efisiensi Pemasaran Produk Madu di Kabupaten Pasuruan. Retrieved from https://fapet.ub.ac.id/wpcontent/uploads/2015/01/Jurnal-Efisiensi-Pemasaran-Produk-Madu-Di-Kab-PasuruanUjang-Indra-T.pdf

Wahyudi, D. P., \& Nuddin, A. (2019). Pengembangan Kelompok Usaha Madu Hutan Di Desa Pappandangan, Polewali Mandar Melalui Program Kemitraan Masyarakat. Jurnal Dedikasi Masyarakat, 2(2), 44-51. doi:10.31850/jdm.v2i2.381

Wibawanti, J. M., Mudawaroch, R. E., \& Pamungkas, S. (2020). Inovasi Pengolahan Produk Turunan Madu Lebah Klanceng Menjadi Bee Polen Kapsul Sebagai Sumber Antioksidan di Desa Jelok Kecamatan Kaligesing Purworejo. Surya Abdimas, 4(1), 19-24. doi:10.37729/abdimas.v4i1.471

Yunita, Pordamantra, \& Pisi, B. A. (2019). Strategi Pengembangan Budidaya Lebah Madu di Kelurahan Kalampangan Kecamatan Sabangau Kota Palangka Raya. Journal Socio Economics Agricultural (J-SEA), 14(1), 62-71. Retrieved from https://ejournal.upr.ac.id/index.php/j-sea/article/view/484/435 